\title{
Matrix Modification for Determination of Gallium by Graphite Furnace Atomic Absorption Spectrometry
}

\author{
Koji Matsusaki and Masayoshi IzUchi ${ }^{\dagger}$ \\ Department of Industrial Chemistry, Technical College, Yamaguchi University, \\ Tokiwadai, Ube 755, Japan
}

Keywords Gallium, atomic absorption spectrometry, graphite furnace, matrix modification, chloride interference

In the determination of volatile elements such as indium and gallium by atomic absorption spectrometry with a graphite furnace, the sensitivities are poor, because the analyte is lost from the graphite furnace before atomization. Therefore, the modification of the matrix by the addition of chemical reagents to the sample solution is necessary to prevent the loss of analyte before atomization by increasing the thermal stability of analyte. In the determination of gallium, not only nickel nitrate ${ }^{1-3}$ and magnesium nitrate ${ }^{4}$ but also hafnium ${ }^{5}$ and ascorbic acid $^{6}$ have been recommended as the matrix modifier.

On the other hand, in the determination of gallium, severe chloride interference is observed. ${ }^{7,8}$ It has been interpreted in terms of the formation of volatile gallium chloride during the drying step and a vapor-phase process during the atomization step. ${ }^{7,-12}$ In our previous work ${ }^{13}$, the mechanisms of halide interferences in the determination of trace elements have been investigated and the ammonium salt of EDTA has been found to be most suitable for removal of these interferences. In the determination of gallium, EDTA ${ }^{14}$ and ammonium sulfate ${ }^{1}$ have been recommended as the removal additive. Nakamura $e t$ al. ${ }^{8}$ have reported that EDTA suppressed the interference by hydrochloric acid, but did not suppress the other metal chloride interference.

In the determination of indium ${ }^{15}$, the addition of a mixture of nickel and aluminum nitrates and ammonium-EDTA has enhanced the indium atomic absorption sensitivity and removed the chloride interference. In the present work, therefore, the enhancement effect on the atomic absorption sensitivity of gallium and the removal effect on the chloride interference in the determination of gallium by the addition of the mixture of metal nitrates and ammonium salt of EDTA have been investigated.

\footnotetext{
† Present address: NEC Yamaguchi Ltd., Higashimagura, Kusunoki, Ube 757-02, Japan
}

\section{Experimental}

\section{Apparatus and reagents}

A Hitachi Model 180-30 atomic absorption spectrometer was used with a Model GA-2B graphite furnace atomizer, an autosampler and a Model 056 chart recorder. A tube-type graphite cell was used and a Hamamatsu-Photonics gallium hollow cathode lamp was used as the radiation source. Deuterium arc background correction was used throughout.

All solutions were prepared from analytical reagentgrade chemicals and demineralized water, and were stored in polyethylene bottles. The stock gallium solution (1000 $\mathrm{mg} \mathrm{l}^{-1}$ ) was prepared by dissolving gallium metal $(99.999 \%$ pure) in the minimum volume of nitric acid and made up in $0.1 \mathrm{~mol}^{-1}$ nitric acid.

\section{Procedure}

A $10-\mu$ l sample solution was deposited in the center of the graphite tube by the autosampler and then dried, ashed and atomized. Argon was used as sheath gas at $2.01 \mathrm{~min}^{-1}$ and carrier gas at $0.11 \mathrm{~min}^{-1}$. The electric current (temperature) and times for drying and atomization were kept the same: dry for $30 \mathrm{~s}$ at $24 \mathrm{~A}\left(\mathrm{ca} .90^{\circ} \mathrm{C}\right)$, atomize for $5 \mathrm{~s}$ at $280 \mathrm{~A}\left(\mathrm{ca} .2800^{\circ} \mathrm{C}\right.$ ). When the sample solution contained EDTA, the ashing time and electric current (temperature) was for $60 \mathrm{~s}$ at $100 \mathrm{~A}\left(\mathrm{ca} .870^{\circ} \mathrm{C}\right)$, in the other cases, for $30 \mathrm{~s}$ at $90 \mathrm{~A}\left(\mathrm{ca} .750^{\circ} \mathrm{C}\right)$. The absorbance signals during the atomization step were recorded at $287.4 \mathrm{~nm}$ (1.3 $\mathrm{nm}$ band width) and the peak height was taken as the analytical signal.

\section{Results and Discussion}

The effects of coexisting nitrate, sulfate and chloride on the atomic absorption of gallium were investigated for salt concentrations from $10^{-4}$ to $10^{-1} \mathrm{~mol}^{-1}$ in acidic medium ( $0.1 \mathrm{moll}^{-1}$ nitric acid). In this case, the solution which contained $0.01 \mathrm{~mol} \mathrm{l}^{-1}$ nickel nitrate was used as the reference solution, because when the testing 
solution contained no metal nitrate or sulfate, the sensitivity of the atomic absorption signal of gallium was very poor and its reproducibility was invariably poor. As shown in Fig. 1, metal nitrates greatly enhance the gallium atomic absorption signal with increasing these concentrations. The sulfates showed similar effects to those by nitrates, but these enhancement efficiencies were less than those by the nitrates. The chlorides at low concentration partly enhanced the

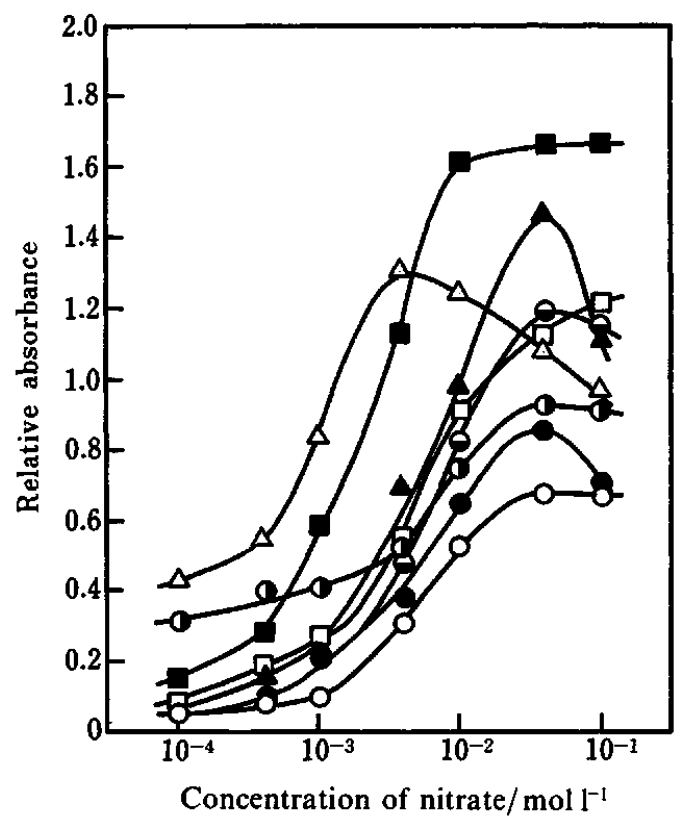

Fig. 1 Effect of some nitrates on the atomic absorbance of gallium $\left(0.2 \mu \mathrm{g} \mathrm{ml}^{-1}\right)$ relative to absorbance in the presence of $0.01 \mathrm{~mol} \mathrm{l}^{-1} \mathrm{Ni}\left(\mathrm{NO}_{3}\right)_{2}$ and $0.1 \mathrm{moll}^{-1} \mathrm{HNO}_{3}$ : $\mathrm{O}, \mathrm{NaNO}_{3}$; ○, $\mathrm{KNO}_{3} ; \boldsymbol{O}, \mathrm{Ca}\left(\mathrm{NO}_{3}\right)_{2} ; \Theta, \mathrm{Mg}\left(\mathrm{NO}_{3}\right)_{2} ; \Delta, \mathrm{Co}\left(\mathrm{NO}_{3}\right)_{2} ; \Delta$, $\mathrm{Ni}\left(\mathrm{NO}_{3}\right)_{2} ; \square, \mathrm{Cu}\left(\mathrm{NO}_{3}\right)_{2} ; \square, \mathrm{Al}\left(\mathrm{NO}_{3}\right)_{3}$.

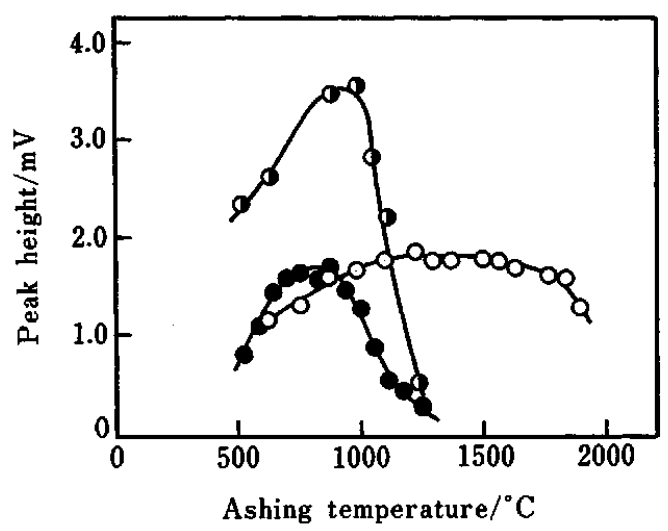

Fig. 2 Effect of ashing temperature on the atomic absorbance of gallium $\left(O, 0.2 \mu \mathrm{g} \mathrm{ml}^{-1} ; 0,2.0 \mu \mathrm{g} \mathrm{ml}^{-1} ; 0,5.0 \mu \mathrm{g} \mathrm{ml}^{-1}\right)$ in the presence of $\mathrm{Ni}\left(\mathrm{NO}_{3}\right)_{2}\left(\mathrm{O}, 1 \times 10^{-2} \mathrm{~mol} \mathrm{l}^{-1} ; \mathrm{O}, 1 \times 10^{-4}\right.$ moll $\mathrm{l}^{-1} ; \mathrm{O}$, no addition) at $\mathrm{pH} 1\left(\mathrm{HNO}_{3}\right)$. gallium signal; however, at high concentration, on the contrary, those greatly suppressed the gallium signal. Since the metal nitrates and sulfates can be easily decomposed to these oxides on heating during the ashing step, the enhancement effects of nitrates and sulfates may be due to these oxides. As the gallium(III) oxide is liable to react with the other metal oxide on heating and to form the mixed oxide ${ }^{16}$, the enhancement effect by the metal nitrates and sulfates may be ascribed to the formation of a more thermostable mixed oxide of gallium, thus resulting in reduction of the analyte loss during preatomization. In order to confirm the thermal stabilizing effect of these metals on the analyte, the effect of ashing temperature on the atomic signal of gallium was examined. The concentration of analyte was varied with the amount of nickel nitrate added. As shown in Fig. 2, the maximum tolerable ashing temperature for gallium in the absence of nickel nitrate and in the presence of $1 \times 10^{-4} \mathrm{~mol} \mathrm{l}^{-1}$ and $2 \times 10^{-2} \mathrm{moll}^{-1}$ nickel nitrate are about 900, 1000 and $1800^{\circ} \mathrm{C}$, respectively. When no nickel nitrate was added to the test solution, the reproducibility of the atomic signal of analyte was very poor. These results are similar to those obtained by Shan et al.' The other metal nitrates showed a similar ashing effect.

The nickel nitrate was chosen as the additive, because the nickel ion is easily converted to EDTA complex in aqueous solution over a wide pH range. When the aluminum nitrate was added together with nickel nitrate, the gallium atomic signal is further enhanced than had resulted from the addition of each nitrate individually. Some other metal nitrates mixed with nickel salt also showed a similar enhancement effect, but these efficiencies were less than that obtained by aluminum salt. Therefore, the mixture salt of $0.02 \mathrm{~mol}$ $\mathrm{l}^{-1}$ nickel and $0.001 \mathrm{~mol}^{-1}$ aluminum nitrates was used as additive. Since the amount of EDTA added is required to be at least a quantity equivalent to the total metal ion contents, the concentration of added metal nitrates could not be so high.

The results described above show that the oxides of nickel and aluminum enhance the sensitivity of atomic absorption of gallium. In the case of adding EDTA, the EDTA binds strongly not only to coexisting cations in the sample solution, but also to the analyte, to form water-soluble complexes. Therefore, the EDTA acts as a masking agent to prevent the formation of volatile gallium chloride which contributes to the chloride interference, and the EDTA complexes of nickel and aluminum can be decomposed to these metal oxides on heating during ashing step.

The addition of ammonium-EDTA together with nickel and aluminum nitrates in order to remove the interferences of various chlorides was investigated. In order to compare with the removal effect, instead of EDTA the addition of nitric acid was also investigated. Plots (a) and (b) in Fig. 3 show the severe interferences by calcium and copper chlorides in the presence of nitric acid. The other chlorides except sodium, 


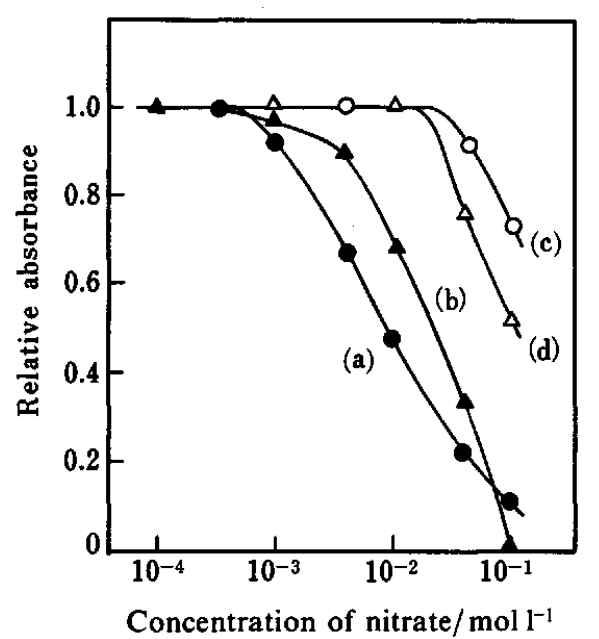

Fig. 3 Effect of chlorides on the atomic absorbance of gallium $\left(0.2 \mu \mathrm{g} \mathrm{ml}^{-1}\right)$ in the presence of $0.02 \mathrm{moll}^{-1} \mathrm{Ni}\left(\mathrm{NO}_{3}\right)_{2}$ and $0.001 \mathrm{moll}^{-1} \mathrm{Al}\left(\mathrm{NO}_{3}\right)_{3}$ relative to absorbance without chloride added: (a) and (b), $0.01 \mathrm{~mol} \mathrm{l}^{-1} \mathrm{HNO}_{3}$ added; (c) and (d), $0.05 \mathrm{~mol} \mathrm{l}^{-1} \operatorname{EDTA}\left(\mathrm{NH}_{4}\right)_{4}$ added; (a) and (c), $\mathrm{CaCl}_{2}$; (b) and (d), $\mathrm{CuCl}_{2}$.

potassium and aluminum salts showed similar results. Plots (c) and (d) show the removal effect of EDTA on the interferences of calcium and copper chlorides. Similar results were observed for other chlorides. When the total metal ion content in the sample solution was within the quantity equivalent to the EDTA added, the chloride interference was almost removed.

In the presence of $0.05 \mathrm{moll}^{-1}$ tetraammoniumEDTA, $0.02 \mathrm{moll}^{-1}$ nickel nitrate and $0.001 \mathrm{~mol} \mathrm{l}^{-1}$ aluminum nitrate, the calibration curve for gallium was prepared. The sensitivity of gallium atomic absorption signal was increased by a factor about of 45 compared to that which resulted in the absence of matrix modifier. The effect of $\mathrm{pH}$ of sample solution on the atomic absorption signal of gallium was investigated in the presence of the matrix modifier described above. The $\mathrm{pH}$ was adjusted with nitric acid and ammonia or sodium hydroxide. No variation in absorbance of gallium was observed between $\mathrm{pH} 2$ and 11 . Such a wide $\mathrm{pH}$ range is very advantageous. But in practice, the best analytical condition must be determined for each case.

\section{References}

1. X.-Q. Shan, Z.-N. Yuan and Z.-M. Ni, Anal. Chem., 57, 857 (1985).

2. S. Hasegawa, T. Kobayashi, F. Hirose and H. Okochi, Bunseki Kagaku, 36, 371 (1987).

3. F. Takekawa and R. Kuroda, Talanta, 35, 737 (1988).

4. D. C. Barron and B. W. Haynes, Analyst [London], 111, 19 (1986).

5. J. Ueda and C. Mizui, Anal. Sci., 4, 417 (1988).

6. P. V. Botha and J. Fazakas, Anal. Chim. Acta, 162, 413 (1984).

7. C. Pelosi and G. Attolini, Anal. Chim. Acta, 84, 179 (1976).

8. K. Nakamura, M. Fujimori, H. Tsuchiya and H. Orii, Anal. Chim. Acta, 138, 129 (1982).

9. K. Dittrich, Talanta, 24, 725 (1977).

10. K. Dittrich, Anal. Chim. Acta, 97,59 (1978).

11. K. Tsunoda, H. Haraguchi and K. Fuwa, Spectrochim. Acta, 35B, 715 (1980).

12. K. Tsunoda, H. Haraguchi and K. Fuwa, Spectrochim. Acta, 40B, 1651 (1985).

13. K. Matsusaki, Anal. Chim. Acta, 141, 233 (1982).

14. K. Kuga, S. Ooyu, E. Kitazume and K. Tsujii, Bunseki Kagaku, 33, E29 (1984).

15. K. Matsusaki, Bunseki Kagaku, 39, 823 (1990).

16. K. Wade and A. J. Banister, "The Chemistry of Aluminium, Gallium, Indium and Thallium", p. 1093, Pergamon Press, Oxford, 1973.

(Received October 1, 1990) (Accepted December 10, 1990) 